\title{
CAMPO DE CONHECIMENTO, VIDA COTIDIANA E A INFORMAÇÃO'
}

\author{
Denise Morado Nascimento
}

\begin{abstract}
Resumo
Neste estudo, pretendemos compreender a informação como prática social inserida no 'mundo comum' de seus atores sociais. Sendo assim, evidenciamos os conceitos da sociologia do conhecimento e da realidade da vida cotidiana dos professores Peter Berger e Thomas Luckmann, e os da teoria do mundo social do sociólogo Pierre Bourdieu. Por fim, relevamos as considerações sobre a necessária interação da Ciência da Informação e as Ciências Sociais.
\end{abstract}

\section{Palavras-chave}

Informação; Cotidiano; Campo Social

\section{INTRODUÇÃO}

Para nortear o entendimento do campo de conhecimento, consideramos, neste trabalho, os conceitos da sociologia do conhecimento e a análise da construção da realidade de Peter Berger e Thomas Luckmann (1985), revelados em seu livro "A construção social da realidade", os conceitos da teoria do mundo social do sociólogo Pierre Bourdieu (1989) e daqueles

\footnotetext{
${ }^{1}$ Artigo originado de trabalho apresentado ao Programa de Pós-Graduação da Escola de Ciência da Informação da Universidade Federal de Minas Gerais, como atividade final da disciplina "Fundamentos Sociais da Informação" ministrada pela Professora Ligia Maria Moreira Dumont, 2. Semestre de 2002.
}

sobre a informação social resgatados por Ana Maria Cardoso (1996) e Aldo Barreto (2002a).

\section{A CONSTRUÇÃO SOCIAL DA}

\section{REALIDADE}

Segundo Berger e Luckmann (1985), é preciso, antes de qualquer coisa, entender os termos "realidade" e "conhecimento" para avançarmos em uma investigação sobre o assunto. Em seu Dicionário de Filosofia, Blackburn (1994) define a realidade como "aquilo que existe", mas coloca a 
questão de se saber o que existe, relacionada às dúvidas de caráter filosófico. Entre elas, se a realidade inclui a mente tal como a matéria, ou a matéria tal como a experiência. O conhecimento, por sua vez, refere-se às questões centrais como sua origem, o lugar da experiência e da razão, além de sua relação com a certeza e o erro.

Berger e Luckmann (1985) desenvolvem sua investigação sobre a sociologia do conhecimento a partir da preocupação com o mundo em que vivemos e o conhecimento que temos desse mundo, deixando para a filosofia a investigação das idéias do mundo e a interpretação teórica de que se tem delas.

Entretanto, mesmo que partamos dos pensamentos teóricos de Berger e Luckmann, é inevitável a alusão filosófica que alimentou a sociologia do conhecimento. Podemos inferir a sociologia do conhecimento como:

[...] o estudo dos fatores sociais que envolvem o aparecimento de sistemas de crença ou as modificações que se dão nesses sistemas através de mudanças de teoria, de experiências e da aceitação de diferentes paradigmas de explicação (BLACKBURN, 1994, p.366).

Berger e Luckmann (1985) indicam os conceitos de "infra-estrutura" (a organização econômica da sociedade e o pensamento humano fundado no trabalho humano) e "super-estrutura" (a organização cultural e as relações sociais produzidas pelo trabalho) de Karl Marx (1818-83) como raízes do estudo da sociologia do conhecimento.

Vejamos também outros autores que fundamentam a sociologia do conhecimento. Friedrich Nietzche (1844-1900) contribui com a idéia intelectual de que todo o comportamento humano é motivado pela "vontade de poder" e o pensamento é o instrumento na luta pela sobrevivência. Mais além, a historicidade do pensamento humano, revelado por Wilhelm Dilthey (18331911), é indicada como precedente da sociologia do conhecimento.

Em um segundo momento, a sociologia do conhecimento de Max Scheler (1874-1928), declara o conhecimento humano existente na sociedade como um a priori à experiência individual, fornecendo a esta sua ordem de significação - a "relativa e natural concepção de mundo". Mesmo que apresentado como "um episódio passageiro" na carreira filosófica de Scheler, esse debate alimentou os estudos de Karl Mannheim (1893-1947), considerado o inaugurador da sociologia do conhecimento em função de seus estudos sobre a relação de todas as facetas ou modos do pensamento humano com as influências econômicas e culturais que os cercam.

Outros vários autores, como Robert Merton, Talcott Parsons, Wright Mills e Theodor Geiger, são citados por Berger e Luckmann como expositores de idéias so- 
bre a sociologia do conhecimento, mas não como colaboradores do desenvolvimento teórico da área, como o fez Mannheim.

Longe de nosso objetivo caminhar historicamente pela sociologia do conhecimento, ou filosoficamente pelas idéias de seus predecessores; interessa-nos, entretanto, reconhecer que os estudos de Berger e Luckmann sobre a sociologia do conhecimento se atêm à compreensão da realidade da sociedade em função da maneira pela qual a realidade da vida é construída: o conhecimento não existe sem o homem social que constrói o seu mundo, isto é, a sua realidade cotidiana - o "conhecimento do senso comum". Como os autores afirmam, essa análise exclusivamente teórica é parte da disciplina empírica da sociologia e se abstém de qualquer compromisso filosófico, epistemológico ou metodológico.

A vida cotidiana apresenta-se como uma realidade interpretada pelos homens e subjetivamente dotada de sentido para eles na medida em que forma um mundo coerente (BERGER, LUCKMANN, 1985, p.35)

A análise da vida cotidiana, feita por Berger e Luckmann, segue as considerações do sociólogo Alfred Schutz (18991959), influenciado conceitualmente pela teoria e método do fundador da fenomenologia, o filósofo Edmund Gustav Albert Husserl (1859-1938). Sua teoria e método representam os seguintes conceitos (MINAYO, 2000, p. 57):

(1) situação - significa o lugar que alguém ocupa na sociedade, o papel que desempenha e suas posições ético-religiosas, intelectuais e política;

(2)experiência biográfica - o homem está situado biograficamente no mundo da vida sobre o qual e no qual deve agir;

(3) conhecimento - sedimentação das experiências e situações vivenciadas;

(4)estoque de conhecimento do ator social - funciona como um marco de referência, através do qual interpreta o mundo e pauta sua ação;

(5)estruturas de relevância - importância que os objetos e os contextos possuem para o sujeito, o que se relaciona com sua bagagem de conhecimento e com a situação biográfica.

Para Schutz, o propósito do cientista social é revelar os significados subjetivos implícitos que penetram no universo dos atores sociais, e descreve o modelo científico a partir dos seguintes princípios (MINAYO, 2000, p. 58):

(1)a intersubjetividade - estamos sempre em relação uns com os outros;

(2)a compreensão - para atingir o mundo do vivido, a ciência tem que apreender as coisas sociais como significativas;

(3) a racionalidade e a internacionalidade - o mundo social é constituído sempre por ações e interações que obedecem a usos, costumes e regras ou que conhecem meios, fins e resultados.

Greene, citado por Bogdan e Biklen (1994), afirma que os fenomenologistas 
acreditam que se tem à disposição múltiplas formas de interpretar as experiências, em função das interações com os outros, e que a realidade não é mais do que o significado das experiências. $\mathrm{Na}$ base desta abordagem, surge a maior crítica que se faz à fenomenologia, segundo Minayo (2000): o desconhecimento dos fenômenos estruturais e ausência de discussão sobre as questões do poder, da dominação, da força e da estratificação social. "Os seres humanos vivem sob o lema crer é poder" (BOGDAN, BIKLEN, 1994, p. 54).

No tratado da sociologia do conhecimento de Berger e Luckmann, a fenomenologia é apontada como influência básica. $E$, a partir daí, é possível entender claramente o caráter apenas descritivo e empírico de seus estudos sobre a realidade da vida cotidiana, portanto, não filosófico.

\section{A VIDA COTIDIANA}

A realidade da vida cotidiana, segundo Berger e Luckmann (1985), é carregada de uma estrutura temporal que fornece historicidade e é constituída por uma ordem de objetos designados como objetos antes da existência do sujeito, tendo seus fenômenos previamente dispostos em padrões independentes da apreensão que deles se têm, mas impostos à apreensão. Além disso, divide-se em setores - "zonas da vida cotidiana", que representam o mundo em que trabalhamos e onde $o$ interesse de seus participantes é intenso e urgente - a "realidade predominante".

Sabemos, também, que o interesse do sujeito por zonas limítrofes da vida cotidiana é gradual e menos direto. A existência de "zonas da vida cotidiana" que direcionam os interesses de cada indivíduo contribui para a compreensão da atuação fragmentada dos atores em campos de conhecimento. Interessa-nos também saber que a realidade da vida cotidiana, assim descrita, fomenta a reprodução e segmentação dessa mesma vida cotidiana, reduzindo as possibilidades de modificação desses atores sociais. Berger e Luckmann consideram a interação social face a face como a mais real e próxima do entendimento da subjetividade do outro, deixando em plano remoto as outras formas de relacionamento. Na medida em que a interação face a face se reduz, a apreensão da vida cotidiana se torna anônima.

Ainda que a interação face a face e a comunicação aconteçam entre os vários atores, é claro que há para cada um uma realidade de vida cotidiana própria e diferente, mesmo que inseridos em uma mesma zona da vida cotidiana, ou em torno de um objetivo comum. Acreditamos que a contínua correspondência entre significados no mesmo mundo que se partilha, torna possível a operacionalização da realidade, mas não assegura, nem explica sua 
transformação continuada. Mesmo assim, Berger e Luckmann (1985) se referem a essa capacidade de transformação como interrupção das rotinas da vida cotidiana o novo conhecimento ou problema -, mas não esclarecem sobre a possibilidade de acesso ao conhecimento e as relações de dominação frente a esse novo conhecimento.

Perguntamos: como é possível analisar a interação social, sem se deixar revelar as questões do poder e da dominação social de um campo social, caracterizado por conflitos existentes em função de atividades interdependentes exercidas por pessoas que agem de forma independente?

A análise fenomenológica se ausenta da contextualização social, política e econômica desses objetos que configuram a realidade da vida cotidiana, e não consideram as relações de poder que provocam as interrupções, isto é, os problemas que se revelam ser a possibilidade da transformação. O conceito de "zona da vida cotidiana" auxilia no entendimento do conhecimento do senso comum, mas apenas se descolado de relações de poder, ou seja, as relações sociais. Sendo assim, o campo de conhecimento não pode se inserir apenas na conceituação de "zona da vida cotidiana", o que, por si só, representaria o abandono de uma análise crítica de sua construção.
Mesmo que saibamos do comprometimento apenas descritivo de Berger e Luckmann, é preciso considerar seus prejuízos frente a uma análise mais abrangente e profunda sobre um campo empírico e suas estruturas sociais. Por outro lado, reconhecemos o mérito do entendimento do conhecimento de senso comum a partir do que se mostra diretamente pela realidade da vida cotidiana.

\section{TEORIA DO MUNDO SOCIAL}

Tomemos como referencial os estudos do sociólogo francês Pierre Bourdieu e sua sociologia reflexiva fundamentada a partir do pensamento relacional como entendimento da realidade, "sob forma de grupos definidos como população, com a noção de classe, ou mesmo de antagonismo entre esses grupos, que sob a forma de um espaço de relações" (BOURDIEU, WACQUANT apud SILVA, 2002, p. 119). As bases conceituais de Bourdieu estão centradas em três aspectos explicitados para a construção do nosso objeto de pesquisa: (1) o conhecimento praxiológico; (2) a noção de habitus; e (3) o conceito de campo.

O primeiro aspecto, o conhecimento praxiológico, apóia-se nos conhecimentos trazidos pelo embate de teorias sociológicas. Bourdieu não vê o conhecimento somente do ponto de vista epistemológico 
(origem, natureza e limites), mas para que ele serve. Nesse sentido, Ortiz (1983) afirma que Bourdieu considera a problemática epistemológica como uma discussão que oscila entre dois tipos de perspectivas antagônicas: o objetivismo, que se baseia nas relações objetivas dos sujeitos, retificado pelo positivismo de Émile Durkheim (18581917); e a fenomenologia que se refere à subjetividade do sujeito, presente na sociologia compreensiva de Max Weber (18641920).

Durkheim, segundo Minayo (2000), foi o primeiro a fundamentar as possibilidades teórico-metodológicas do positivismo para a compreensão da sociedade, considerando a sociedade como 'coisa' - a análise funcional é o alicerce da sua formulação teórica sociológica. Para esse sociólogo francês, seguidor de Auguste Comte (1798-1857), a experiência e idéias do cientista sobre a realidade social são descartáveis, devendo-se criar métodos para que os fatos sociais possam ser descritos e classificados com precisão (MINAYO, 2000).

[...] a sociedade é um fenômeno moral, na medida em que os modos de pensar, perceber, sentir e agir incluem elementos de coerção e obrigação, constituindo assim uma consciência coletiva que se expressa na religião, na divisão do trabalho e nas instituições (DURKHEIM apud MINAYO, 2000, p. 44).

[...] os fatos sociais devem ser explicados por outros fatos sociais
(DURKHEIM apud BLACKBURN, 1994, p. 109)

A sociologia compreensiva aparece como uma segunda visão da sociedade e contra os princípios do positivismo, "[...] privilegiando a compreensão e a inteligibilidade como propriedades específicas dos fenômenos sociais, mostrando que o significado e a intencionalidade os separam dos fenômenos naturais" (MINAYO, 2000, p. 50).

A sociologia exige um ponto de vista específico já que os fatos de que se ocupa implicam um genêro de causação desconhecido das ciências da natureza. [...] È uma ciência que se preocupa com a compreensão interpretativa da ação social, para chegar à explicação causal de seu curso e de seus efeitos. Em 'ação' está incluído todo o comportamento humano quando e até onde a ação individual the atribui um significado subjetivo (WEBER apud MINAYO, 2000, p.50).

As metodologias da sociologia compreensiva, propostas pelo sociólogo e filósofo alemão Weber (apud MINAYO, 2000, p.51), apresentam dois princípios: a neutralidade do valor e a construção do tipo-ideal. Este último se configura como artifícios criados pelo cientista para ordenar os fenômenos, para indicar suas articulações e seu sentido; sintetizam e evidenciam os traços típicos, originais de determinado fenômeno tornando-o inteligível (MINAYO, 2000).

Nesse cenário, o marxismo emerge como oposição entre correntes. Segundo Blackburn (1994), o conceito filosófico de 
práxis tem sido usado, desde os tempos de Aristóteles, como uma das três atividades básicas dos seres humanos, além da teoria e da produção artística. O autor continua, afirmando que em Kant o termo práxis se designa para a aplicação de uma teoria em uma experiência, isto é, uma reflexão sobre a razão prática. Mas explicita que somente com Karl Marx (1818-83), a práxis se torna central, como entendimento da subordinação da teoria à prática relacionando-se com a incapacidade da razão resolver as contradições removidas pelo progresso dialético da história. Para Minayo (2000), no que diz respeito ao processo de desenvolvimento social dentro da perspectiva marxista, há duas distinções: o materialismo histórico, significando a teoria da transição histórica, e o materialismo dialético, referindo-se ao método de abordagem deste real.

Por isso, reconhecemos em Bourdieu o diálogo crítico que ultrapassa os limites das três vertentes sociológicas - o conhecimento praxiológico - representando a percepção dialética entre a teoria e a prática, entre homem e história, entre ator e estrutura, entre agente social e sociedade, e tendo por objeto:

[...] não somente o sistema de relações objetivas que o modo de conhecimento objetivista constrói, mas também as relações dialéticas entre essas estruturas objetivas e as disposições estruturadas nas quais elas se atualizam e que tendem a reproduzi-las, isto é, o duplo processo de interiorização da exterioridade e de exteriorização da interioridade (BOURDIEU, 1983a, p. 47).

Estas estruturas constitutivas de um meio social produzem o habitus - segundo aspecto da abordagem de Bourdieu - o reconhecimento do espaço social ocupado por cada ator social. Segundo Marteleto (1995, p. 15), o habitus é uma forma concreta de expressão social de uma experiência cultural acumulada, um esquema de percepção e ação adquirido pela história social de cada um, e o processo e o resultado de um aprendizado.

O conceito de habitus tem sua origem no conceito de ethos de Aristóteles (384322 a.C.), como expressão de um modo de ser do homem em relação a si próprio, ao outro e ao mundo. O uso desse termo partiu de Erwin Panofsky (1892-1968), teórico alemão da história da arte, atrelado ao pensamento escolástico como base para o entendimento da "unidade real de espírito" e da uniformização das diversidades individuais expressas na arquitetura gótica, presentes em sua obra Arquitetura gótica e a escolástica. Segundo Silva (2002, p.116), Panofsky teve influências dos mestres pertencentes à escola neokantista e estudiosos como Simmel, Dilthey e Weber, ambicionando "[...] transformar a história da arte em uma disciplina humanística (não no sentido de uma ciência humana, mas no sentido de uma história do espírito humano)". 
Bourdieu reinterpreta o conceito de habitus perpassando pela evidência das capacidades criadoras e inventivas, levando-o "[...] a operar uma mediação entre os comportamentos individuais e as relações objetivas" (SILVA, 2002, p. 119):

[...] cada agente, quer saiba ou não, quer queira ou não, é produtor e reprodutor de sentido objetivo porque suas ações e suas obras são produto de um modus operandi do qual ele não é o produtor e do qual ele não possui o domínio consciente; as ações encerram, pois, uma 'intenção objetiva', como diria a escolástica, que ultrapassa sempre as intenções conscientes (BOURDIEU apud ORTIZ, 1983, p. 15).

Inegavelmente, as condições do exercício do habitus estão relacionadas a uma situação social, econômica, política "estado particular dessa estrutura". É o que está no ator, no sujeito, na posição social, na biografia cultural e na história individual, conformada essencialmente pela sua trajetória social dentro da família (habitus primário) e pela herança cultural e formação educacional da escola (habitus secundário). O habitus é algo que se define pela percepção da situação que o determina, pela interioridade adquirida e pela exterioridade expressa. Sendo assim, os ajustamentos incessantemente impostos pelas necessidades de adaptação às situações novas e imprevistas, podem determinar transformações do habitus. Quando as condições objetivas da realização não são dadas, o habitus, contrariado pela situação, pode ser o lugar de forças inventivas e de capacidades criativas que se exprimem no momento em que as condições objetivas se apresentam (BOURDIEU, 1983b). Segundo Bourdieu (1983a, p. 61), habitus são:

[...] sistemas de disposições duráveis, estruturas estruturadas predispostas a funcionar como estruturas estruturantes, isto é, como princípio gerador e estruturador das práticas e das representações que podem ser objetivamente "reguladas" e "regulares" sem ser o produto da obediência a regras, objetivamente adaptadas a seu fim sem supor a intenção consciente dos fins e o domínio expresso das operações necessárias para atingi-los e coletivamente orquestradas, sem ser o produto da ação organizadora de um regente.

Situar um campo de conhecimento como expressão cultural de uma época inserida em uma "estrutura objetiva que define as condições sociais de produção do habitus" (BOURDIEU, 1983a, p. 65), evita a análise puramente filosófica, permitindo-nos perceber as cumplicidades e o jogo de relações entre os atores, isto é, aqueles que exercem o poder e aqueles que deixam o poder ser exercido - o poder simbólico. Acreditamos que, assim, estaremos assegurando a análise das condições do exercício do habitus, das questões do poder, da dominação, da força e da estratificação social presente nos campos de conhecimento.

Para compreender amplamente essa possibilidade é necessário entender, es- 
sencialmente, o terceiro aspecto da abordagem de Bourdieu - o conceito de campo, como sendo a situação particular objetivamente estruturada que enfrenta um ator social específico, mas não como resultado de ações individuais dos agentes (ORTIZ, 1983). O campo se caracteriza pelo conjunto de ações, representações e interações sociais, enquanto o habitus se aplica ao sujeito embebido por seu 'montante' de conhecimento e a posição social determinada por esse - o capital social. O máximo de capital social determina uma posição no campo dos dominantes, e a falta de capital social insere o indivíduo no campo dos dominados.

A divisão do campo social em dominantes e dominados implica uma distinção entre ortodoxia e heterodoxia [...]. Ao pólo dominante correspondem as práticas de uma ortodoxia que pretende conservar intacto o capital social acumulado; ao pólo dominado, as práticas heterodoxas que tendem a desacreditar os detentores reais de um capital legítimo. Os agentes que se situam junto à ortodoxia devem, para conservar sua posição, secretar uma série de instituições e de mecanismos que assegurem seu estatuto de dominação (ORTIZ, 1983, p.22).

A história do indivíduo, inserida dentro de uma história coletiva, apresenta suas variáveis e diferenças, e são estas que caracterizam as possibilidades de diferentes percepções, trajetórias, propósitos e apreciações em cada campo - da ciência, da arte, do poder, da cultura, da política, da religião, da construção civil, etc. Lembra- mos que a informação está associada a um conjunto de atividades exercidas pelo e para o homem, e por isso, não pode estar separado das características físicas e contextuais e, essencialmente, das peculiaridades de seus atores executores da estrutura, que exercem seus papéis em seus espaços sociais e culturais.

Com o intuito de analisar a realidade de um campo, isto é, um sistema de relações, é necessário entender as condições sociais de produção deste habitus, que geram as práticas de trabalho. Entendemos que, pelas diversas condições sociais dos atores sociais, existem igualmente diferentes subjetividades, oposições e conflitos, relações de força, interesses e estratégias.

\section{INFORMAÇÃO SOCIAL}

Segundo Cardoso (1994), devemos entender todo e qualquer processo de produção, organização e consumo de informação como social, já que ele acontece entre grupos, segmentos e classes, ou seja, a sociedade e suas relações sociais. Além de a autora colocar nosso objeto de estudo - a informação - sob os refletores da prática social, ela explicita duas dimensões intrinsecamente conectadas: a pessoal e a coletiva.

A dimensão pessoal da informação manifesta-se pelo acervo de soluções e interpretações que acumu- 
lamos no desenrolar de nossa biografia, através daquilo que experienciamos e que nos fornece pistas para lidarmos com novas experiências. A dimensão coletiva identificase com fragmentos do conhecimento produzido desde que o mundo é mundo, ou seja, as sistematizações e interpretações de experiências disponibilizadas socialmente, ainda que não se possa deixar de destacar que tal disponibilização ocorre diversamente entre os indivíduos em função dos diferentes lugares que ocupam na estrutura social (CARDOSO, 1996, p.72).

Nesse bojo, podemos considerar que a informação associada ao conhecimento e à comunicação, é apenas reconhecida nos limites de um mesmo mundo comum dentro dos horizontes da pré-compreensão. Gonzáles de Gómez (2002, p. 32) afirma que "[...] ações e discursos são concernentes àquilo que interessa a um grupo de pessoas e que é diferente para cada grupo, já que é de seu interesse, o que está entre eles e os vincula de algum modo".

No domínio sócio-histórico, a informação é sempre uma resposta que nos é dada por uma determinada tradição cultural, na qual vivemos e nos sentimos seguros. Ela é, nesse sentido, a expressão simbólica materializada em instituições, discursos e práticas, de uma verdade. É ainda o elemento de continuidade do passado, reelaborado e reinterpretado à luz do tempo presente que nos organiza e constitui o princípio da nossa identidade, no qual estão pautadas nossa teoria e nossa prática. (MARTELETO, 1994, p.133).

Parece inevitável relacionarmos este "mundo que pertence a todos" ao conceito de campo ou à realidade da vida cotidiana, mesmo que amparados por diferentes proposições conceituais de seus autores: Bourdieu se referindo ao habitus e ao capital social, e Berger e Luckmann à realidade da vida cotidiana e ao conhecimento de senso comum.

Além disso, podemos estabelecer o ponto comum de tratar, captar e interpretar a informação, segundo Cardoso (1994), como movimento dialético entre a sociedade e o homem, ou em outras palavras, entre os produtos humano e social. Se a informação, assim, se configura como social, Cardoso sugere a construção do objeto de estudo sempre referenciada à historicidade dos sujeitos cognoscentes e dos objetos cognoscíveis, à totalidade dos fenômenos sociais e à tensionalidade constante que está presente na sociedade. Justificamos, sob esse ponto de vista, a necessidade de se situar culturalmente e historicamente o campo de conhecimento dentro de um contexto sociológico que permita o entendimento do mundo.

\section{FINALIZANDO...}

Podemos considerar, então, que a análise sociológica do "mundo da vida cotidiana" de um campo, aliada ao entendimento das relações sociais de seus atores sociais, é que permitirá a leitura históricosocial de suas práticas informacionais.

Receber, gerar e transferir informações sobre si mesmo e sobre o 
mundo são atividades sem as quais não se poderia pensar o homem, pois é através dessas ações que ele constrói e reconstrói seu projeto de civilização. Assim, no nível das sociedades históricas, a produção e a reprodução de artefatos culturais realiza-se a partir do modo informacional. Nessas sociedades, toda prática social pode ser considerada como uma prática informacional, pois toda interação humana pressupõe recepção, geração ou transferência de informação. Em contrapartida, deve-se salientar que deve ser salientado que o funcionamento dos campos sociais seja integralmente informacional ou baseado apenas nas práticas informacionais, pois, além dessas práticas existem, nos campos sociais, as condições de produção, os objetos, os valores e sentidos que acompanham as informações (ARAÚJO, 2001).

Assim, acreditamos que os conceitos de conhecimento praxiológico, habitus e campo, se configuram como elos conceituais para a construção do objeto desta pesquisa. Façamos, por fim, reflexões sobre o campo da Ciência da Informação, já que é sob essa ótica que nossos estudos serão guiados. Barreto (2002a), em artigo sobre a instituição da ciência da informação, revela seus propósitos de reflexão sobre o campo que estuda a ação mediadora entre informação e conhecimento acontecido no indivíduo:

[...] esta é a condição da informação, a de harmonizar o mundo. Como elemento organizador, a informação referencia o homem a seu destino; desde antes de seu nascimento, com sua identidade genética, e durante sua existência pela capacidade em relacionar suas memórias do passado com uma perspectiva de futuro e assim esta- belecer diretrizes para realizar sua aventura individual no espaço e no tempo (Barreto, 2002a)

Em uma outra fala, Barreto (2002b, p. 49) já havia explicitado a informação como aquilo que "[...] se qualifica como um instrumento modificador da consciência do indivíduo e de seu grupo social, pois sintoniza o homem com a memória de seu passado e com as perspectivas de seu futuro". Da mesma forma, percebemos esse olhar sob o campo da Ciência da Informação em Marteleto (2002, p. 102) como:

[...] a relação entre informação e sociedade ou conhecimento e sociedade, não apenas como subtópicos de estudo de um campo ou disciplina, mas como modo essencial de constituição dos fenômenos culturais, discursivos, simbólicos, dos sentidos, e a relevância interdisciplinar das teorias sociais na compreensão das questões práticas e teóricas da informação.

Marteleto ressalta (2002, p.105):

[...] Informação não é processo, matéria ou entidade separada das práticas e representações de sujeitos vivendo e interagindo na sociedade, e inseridos em determinados espaços e contextos culturais.

Sabemos que o campo da informação hoje permeia a expressão conceitual legitimada em sua produção científica e acadêmica e a configuração necessária para a sua sustentação envolvendo a gênese, a natureza e a especificidade de seu objeto.

Ainda que os desafios impostos à Ciência da Informação, isto é, as interações com outros campos como a sociologia, a antropologia, a lingüística, a comunicação 
e a filosofia, seus limites, definições e pressupostos, além de suas relações com as tecnologias da informação sejam considerados, partimos da premissa inicial que a pesquisa do fenômeno da informação está implantada, segundo órgãos oficiais (ver $\mathrm{CNPq}$ ) que classificam as áreas de conhecimento, dentro dos domínios das Ciências Sociais Aplicadas. González de Gómez (2000) afirma que "o objeto da Ciência da Informação tem que ser considerado como uma construção de significado de segundo grau a partir das práticas e ações sociais de informação, que constituem seu domínio fenomênico".

Dadas as condições fenomênicas do objeto da Ciência da Informação, a informação, as Ciências Sociais se apresentam como o campo comum e orientador dos fundamentos de sua investigação. Nesse sentido, os fundamentos das Ciências Sociais como respostas à problemática da Ciência da Informação, permitem o conhecimento sobre as relações entre indivíduo e sociedade.

\section{REFERÊNCIAS}

ARAÚJO, Eliany Alvarenga de. A construção social da informação: dinâmicas e contextos. DataGramaZero: Revista de Ciência da Informação, v.2, n.5, out. 2001. Disponível em: <http://www.dgz.org.br/out01/F_I_art.htm>. Acesso em Fev. 2003.

BARRETO, Aldo de Albuquerque. A condição da informação. São Paulo em Perspec- tiva, v.16, n.3, jul./set. 2002a. Disponível em: <http://www.scielo.br>. Acesso em Fev. 2003.

. Transferência da informação para o conhecimento. In: AQUINO, M. A. O campo da ciência da informação: gênese, conexões e especificidades. João Pessoa: Editora Universitária/UFPB, 2002b. p.4959.

BERGER, Peter L.; LUCKMANN, Thomas. A construção social da realidade. 22. ed. Petrópolis: Vozes, 1985.

BLACKBURN, Simon. Dicionário Oxford de filosofia. Rio de Janeiro: Jorge Zahar Editores, 1994.

BOGDAN, Robert; BIKLEN, Sari. Investigação qualitativa em educação: uma introdução à teoria e aos métodos. Porto: Porto Editora, 1994.

BOURDIEU, Pierre. Esboço de uma teoria da prática. In: ORTIZ, R. (org.) Pierre Bourdieu: sociologia. São Paulo: Ática, 1983a, p.46-81.

. O poder simbólico. Rio de Janeiro: Bertrand Brasil, 1989.

O mercado lingüístico. In:

Questões de sociologia. Rio de Janeiro: Marco Zero, 1983b, p.95-107.

CARDOSO, Ana Maria Pereira. Retomando possibilidades conceituais: uma contribuição à sistematização do campo da informação social. Rev. Esc. Bibliot. UFMG, Belo Horizonte, v.23, n.2, p.107-114, jul./dez. 1994.

. Pós-modernidade e informação: conceitos complementares? Perspectivas em Ciência da Informação, Belo Horizonte, v.1, n.1, p.63-79, jan.jun.1996.

GONZÀLEZ de GÓMEZ, Maria Nélida. Dos estudos sociais da informação aos estudos do social desde o ponto de vista da informação. In: AQUINO, M. A. (Org.) O campo da ciência da informação: gênese, cone- 
xões e especificidades. João Pessoa: Editora Universitária/UFPB, 2002. p. 25-47.

Metodologia de pesquisa no campo da Ciência da Informação. DataGramaZero: Revista de Ciência da Informação, v.1, n.6, dez. 2000. Disponível em <http://www.dgzero.org/dez00/Art_03.htm> Acesso em 15/07/2002.

MARTELETO, Regina Maria. Conhecimento e Sociedade: pressupostos da antropologia da informação. In: AQUINO, M. A. O campo da ciência da informação: gênese, conexões e especificidades. João Pessoa: Editora Universitária/UFPB, 2002. p.101115.

- Cultura, educação, distribuição social dos bens simbólicos e excedente informacional. Informare: Cad. Prog. PósGraduação Ciência Informação, Rio de Janeiro, v.1, n.2, p.11-23, jul.dez.1995.

Cultura da modernidade: discursos e práticas informacionais. Rev. Esc. Bibliot. UFMG, v.23, n.2, p.115-137, jul./dez. 1994.

MINAYO Maria Cecília de Souza. O desafio do conhecimento: pesquisa qualitativa em saúde. 7.ed. São Paulo: HucitecAbrasco, 2000.

ORTIZ, Renato. Pierre Bourdieu: sociologia. São Paulo: Ática, 1983.

SILVA, Helenice Rodrigues da. Fragmentos da história intelectual. Campinas: Papirus, 2002.

\section{Denise Morado Nascimento}

Professora Adjunta da Escola de Arquitetura da UFMG. Arquiteta. Mestre em Arquitetura (University of York - Inglaterra). Doutora em Ciência da Informação (UFMG) dmorado@uol.com.br

\section{Title}

Daily life, Information and the Knowledge Field

\begin{abstract}
The main objective of this study is to understand the information as a social practice which belongs to a common world shared by the social actors. In this sense, the study follows the concepts of knowledge sociology and the daily life reality of Peter Berger and Thomas Luckmann and also the social world theory from the sociologist Pierre Bourdieu. Finally the necessary interaction between the Social Sciences and the Information Science is revealed.
\end{abstract}

\section{Keywords}

Information; Daily Life, Social Field

\section{Titulo}

Campo del conocimiento, vida cotidiana y la información

\section{Resumen}

En este estudio, pretendemos comprender la información como práctica social inserida en el 'mundo común' de sus actores sociales. Así siendo, evidenciamos los conceptos de la sociología del conocimiento y de la realidad de la vida cotidiana de los maestros Peter Berger y Thomas Luckmann, y los de la teoría del mundo social del sociólogo Pierre Bourdieu. Al final, resaltamos las consideraciones sobre la necesaria interación de la Ciencia de la Información y las Ciencias Sociales.

\section{Palabras clave}

Información; Cotidiano, Campo Social 